\title{
Manuela Águeda García Garrido, Fray Juan Márquez (1564-1621). Un maestro de la Reforma cató- lica, Huelva, Publicaciones de la Universidad de Huelva, 2021, 508 pp. ISBN: 978-84-18628-61-0
}

\section{Ofelia Rey Castelao}

https://orcid.org/0000-0002-9720-8486

Universidad de Santiago de Compostela

ESPAÑA

ofelia.rey@usc.es

[Hipogrifo, (issn: 2328-1308), 9.2, 2021, pp. 1145-1148]

Recibido: 04-08-2021 / Aceptado: 20-08-2021

DOl: http://dx.doi.org/10.13035/H.2021.09.02.80

La figura y la obra del agustino fray Juan Márquez (1564-1621) no contaba hasta ahora con la monografía que merecía, como sucede con otros personajes del período posterior al final del Concilio de Trento a los que se suele tildar, sin más, de religiosos contra-reformistas y anti-maquiavélicos, como si respondiesen todos a un modelo impuesto, el de una ortodoxia monolítica que no dejaba margen a otra originalidad que las agudezas dialécticas y las florituras teológicas. Oscurecidos por el fulgor del Siglo de Oro literario, muchos autores de temas religiosos, y aún políticos, solo han sido objeto de estudios breves que, o bien tratan de corroborar aquella clasificación o de definir una generación, o, al contrario, de rescatar inmerecidos valores, lo que responde casi siempre a reivindicaciones localistas o, al tratarse de regulares, de sus respectivas órdenes religiosas.

Así pues, fray Juan Márquez, siendo uno de los religiosos más destacados de la orden de San Agustín, predicador de renombre y un autor de gran relevancia del pensamiento político barroco, carecía de un análisis en profundidad. Lo que resulta sorprendente por cuanto sus obras más importantes, Los dos estados de la espiritual Hierusalen (1602) y El gobernador cristiano (1612), las hallamos con relativa facilidad en las bibliotecas institucionales y privadas de los siglos modernos 
-no en vano se reimprimieron y se tradujeron-, y por su calidad literaria merecieron encendidos elogios de autores coetáneos y decimonónicos. Pero lo cierto es que acabó eclipsado en los libros de literatura e Historia.

La autora, Manuela Águeda García Garrido, profesora en la Universidad francesa de Caen, tiene tras de sí una obra temáticamente muy vinculada a la predicación y la oratoria barrocas, caracterizada por su rigor científico y por su excelente estilo. Son las mismas características del libro que reseñamos: una enorme base documental, buscada en archivos y bibliotecas muy diversos; un tratamiento metodológico adecuado y sólido de las fuentes documentales; y una exposición académica clara, sistemática y potente. El esfuerzo realizado para localizar la documentación que diese luz a la vida y a la trayectoria del agustino es fácil de valorar por quienes hayan trabajado cualquier tema relacionado con las órdenes religiosas, toda vez que la dispersión de los archivos en la exclaustración de 1835 y las pérdidas motivadas por los procesos desamortizadores, dificultan cualquier indagación, como sucedía precisamente en este caso. Tal empeño se ha visto recompensado con la reconstrucción de la vida de fray Juan, poniendo piezas clave de ese puzle como el expediente genealógico y de costumbres que sobre él se presentó en 1616 a la Cámara de Castilla para optar al cargo de predicador de Felipe III, por solo mencionar una que García Garrido considera indispensable.

La obra se divide en dos partes que recorren la existencia del agustino desde su nacimiento en Madrid, en el seno de una familia que había encontrado su acomodo entre las redes del ámbito cortesano y que tenía recursos suficientes para ofrecerle una formación privilegiada. La primera hace un seguimiento exhaustivo del origen, patria y familia del biografiado. Hijo de un escribano de cámara del rey -dueño de su oficio por compra y de una fortuna considerable-, Juan Márquez optó sin embargo por dejar el siglo. Nacer en la Villa y Corte y en esa familia pudo haberlo inclinado a seguir una asegurada carrera en la administración, pero el descubrimiento de lo religioso irrumpió temprano en su vida, probablemente a través de lecturas, de modo que decidió entrar en la orden de San Agustín; la renuncia a su herencia legítima, obligada en estos casos, se vio compensada con la percepción de una renta para mejorar su condición dentro del convento, lo que también era frecuente entre religiosos de familias con dinero. El progreso social y económico de los Márquez fue sin duda capital en la fase formativa del futuro predicador: en el capítulo dedicado por la autora a esa fase se subraya «la forja de un hombre en el contexto postridentino» y los itinerarios vitales, urbanos, por supuesto, de un hombre moderno, para lo cual la autora estudia, no solo el aprendizaje y la formación previa e inmediata a la entrada en religión, sino la creación y afianzamiento de su bagaje intelectual mediante la reconstrucción de sus lecturas y de su biblioteca inmaterial.

Esa primera parte, titulada «el hombre constante: vocación y disciplina», tiene su colofón en el ingreso de Juan Márquez en el casa salmantina -madre de la observancia- de una orden que, más allá de su prestigio y el de sus maestros, vivía una fase de constantes diferencias entre el papado y el general agustino. Fray Juan fue «testimonio ocular de aquellos desacuerdos que atañían a cuestiones puramente jurisdiccionales y que nunca mermaron la voluntad reformadora de los frailes en 
la ciudad del Tormes» (p. 139), pero que alteraban la vida interna de la comunidad; de ahí que «el afán de la monarquía por supervisar el comportamiento monacal a través de la estructura eclesial, hizo que los agustinos...quedasen supeditados a la férrea autoridad del prior y el provincial» y estos al propio monarca (p. 147). La explicación de ese agitado mundillo así como la ciudad de Salamanca, su obispo y el gobierno eclesiástico, la Universidad y su ambiente religioso y cultural, es esencial para entender la trayectoria de fray Juan, entre el silencio de la celda y la vida comunitaria, y las dificultades del gobierno espiritual en su período como prior.

Los pasos constantes del fraile se conducían sin duda siguiendo la ambición de notoriedad que tantos miembros de las órdenes religiosas ocultaron bajo una apariencia de humildad y de obediencia debida. Así pues, llegó un momento en que fray Juan debía centrarse en tejer su entramado clientelar, el cual se constituyó en torno a la figura del futuro valido, el duque de Lerma; un gesto inequívoco fue la dedicatoria de Espiritual Hierusalem al duque de Uceda, hijo de aquel: el agustino buscaba sin duda recompensa a su obra y a la aplicación de su padre a los servicios a la Corona. La Corte, estuviera en Valladolid o en Madrid, sería el nuevo escenario vital de fray Juan, y la asunción de tareas que le diesen visibilidad -entre otras, calificador de la Inquisición-, procurando mantenerse al margen de las banderías en el seno de su orden «a sabiendas de que su única salida era fraguarse una carrera hacia la Real capilla» (p. 181), para lo que eran esenciales las redes antes mencionadas y las prácticas de sociabilidad que las afianzaban.

La segunda parte de la obra responde a un título muy sugerente «Divina lengua en cátedra y púlpito», y sitúa a fray Juan entre el aula y el claustro en la Universidad de Salamanca, inmerso en la cátedra, en las responsabilidades en su orden y en las disensiones que esta sostenía internamente y con otras instancias, manteniendo siempre su voluntad de implicarse lo menos posible y de conservar sus opciones personales. En las páginas dedicadas a la Universidad destacan las que exponen con gran eficacia el ambiente religioso entre el espectáculo y la solemnidad: la fiesta religiosa en la que fray Juan tuvo una intensa participación, ya en la gestión del prolífico calendario festivo, ya en la predicación, no en vano «el rector no podía acudir a mejor candidato que al padre Márquez para anunciar albricias, visitas reales, aclamar la gracia de Dios o festejar beatificaciones» (p. 273).

Fue precisamente su condición de orador y de autor de sermones lo que llevaría al agustino a ser candidato a predicador real. No se conservan los sermones manuscritos de fray Juan, pero en ese camino hacia la Corte escribió y publicó su obra más conocida, El gobernador cristiano, impresa en Salamanca en 1612, obra que «engrosaba la nómina de los muchos textos que vieron la luz en la primera mitad del siglo XVII sobre los fundamentos teóricos de la monarquía hispánica y su organización político-administrativa, en particular, la naturaleza y potencialidad de la maquinaria consultiva»; como subraya la autora, se trata de un escrito «plagado de apotegmas, exempla y silogismos escolásticos que pretendían infundir veracidad a una argumentación puramente exegética» (p. 289). Como García Garrido afirma en la introducción, el padre Márquez se oponía a las ideas de Maquiavelo y de Jean Bodin, y «su postura siempre fue contraria a toda manifestación política que pusie- 
se en peligro la moral cristiana por lo que nunca vaciló en situar el interés del bien común por encima del individual» (p. 27). Sin duda se trata de la obra más conocida de Márquez, aunque también escribió textos de notable calidad sobre historia de la orden y vidas de algunos de sus miembros.

Los dos últimos capítulos están dedicados a explicar el papel jugado por los agustinos en la Corte de Felipe III, a la relevancia que en esta tenía el oficio de predicador y a la impronta agustiniana en la predicación cortesana. Predicador real desde 1617, fray Juan no entró a formar parte de la Real Capilla al seleccionar a otros el Consejo Real, basándose en que no había estado veinte años en la cátedra para poder jubilarse; este no era asunto menor por cuanto la orden agustina había invertido una elevada cantidad de dinero en dotar ese puesto docente; lo cierto es que para mover los hilos era preciso estar en Madrid y su residencia en Salamanca jugaba en contra de fray Juan, ya que no podía influir en las camarillas cortesanas y la caída de Lerma era de lo menos conveniente. La muerte del padre Márquez se produjo el mismo año que la de Felipe III.

Los anexos del libro, las ilustraciones, la cronología y las fuentes (pp. 389-468) son de gran utilidad para ubicar al biografiado en su contexto familiar, comunitario, religioso, espacial e intelectual. Por afinidad de intereses, recomendamos el capítulo dedicado a la biblioteca de fray Juan basado en el análisis de los autores y obras citados por este en Los dos estados de la espiritual Hierusalen; es una opción metodológica poco empleada en la historiografía sobre la lectura por su dificultad, cuando es imprescindible para un acercamiento lo más profundo posible al instrumental intelectual de cualquier autor.

En definitiva, el libro de Manuela Águeda García Garrido es un recorrido integral, denso y bien contextualizado sobre la figura del agustino padre Márquez, teólogo, historiador eclesiástico, tratadista político, catedrático salmantino, predicador real, calificador del Santo Oficio, además de titular de cargos en su orden religiosa. Todo lo cual llevó a cabo con brillantez en medio de las dificultades propias del ambiente de los regulares en el período pos-tridentino y del cambio de contexto político tras la muerte de Felipe II. La obra de fray Juan, rápidamente traducida, le dio una importante proyección internacional al hacerse eco de las controversias políticoreligiosas de su tiempo. A pesar de esto y del gran valor literario de sus escritos, no había sido objeto de un estudio monográfico de la calidad del que hemos comentado. 